\title{
AN EXPLORATORY INQUIRY ON THE DECISION PROCESS OF PONZI SCHEME INVESTOR'S: A QUALITATIVE CASE STUDY APPROACH
}

\author{
Muhammad Takiyuddin Abdul Ghani*, Bahyah Abdul Halim, and \\ Syamsul Azri Abdul Rahman \\ *Corresponding Author
}

\begin{abstract}
This qualitative research investigates the decision process of the Ponzi scheme investor using the Engel-Blackwell-Miniard Model as the underlying theory which guided the design of this study. The investors' decision process was described using a proposed framework that was adapted from the standard EBM procedure. Seven investors from three different Ponzi investment scheme was interviewed using a semistructured, face-to-face interviews technique and the transcript verbatim was interpreted using ATLAS.ti. The data analysis was conducted using the directed content analysis approach. The supporting evidence reveals that the decision process of Ponzi scheme investors fit with the proposed framework which consists of (1) need recognition, (2) information search, (3) alternative evaluation, and (4) act to invest. In conclusion, this study provides an alternative perspective in investigating the decision process of the Ponzi scheme which can be explained using the consumer behavior theory.
\end{abstract}

Key words: Decision Process; EBM Model; Ponzi Investment Scheme; Investor; Qualitative Case Study.

Cite this Article: Muhammad Takiyuddin Abdul Ghani, Bahyah Bt Halim, and Syamsul Azri Abdul Rahman, An Exploratory Inquiry on the Decision Process of Ponzi Scheme Investor's: A Qualitative Case Study Approach, International Journal of Management, 11(12), 2020, pp 220-236.

http://iaeme.com/Home/issue/IJM?Volume=11\&Issue $=12$

\section{INTRODUCTION}

Perhaps one of the greatest puzzles that remained resolved in Ponzi scheme investment is the question of; why investors invest in such fraudulent scheme? This unresolved "mystery" has left our society especially the authority befuddled. And yet, we still have no relevant piece of 
the answer to complete that puzzle. Maybe we are not passionate enough to seek the solution or maybe we were looking at the wrong perspective.

This issue has been around since the $18^{\text {th }}$ century in which John Law articulated the first ever fraudulent scheme in France that eventually lead to a financial downturn that known as the Mississippi Bubble (Cortes \& Vargas, 2016). The modern example of the catastrophic effect of Ponzi investment is the collapse of the Albanian economy in 1997. As discussed in Abdul Ghani and Abdul Halim (2017), it is beyond doubt that this issue must be addressed persistently and consistently.

So much has been done in the past to understand Ponzi scheme investment. Researchers had studied Ponzi scheme investor from multiple context such as the perpetrator (Trahan et al., 2005; Naylor, 2007; Jory \& Perry,2011; Frankel, 2012; Lewis, 2012; Reurink, 2018), the participants (Sadiraj \& Schram,2001; Loyle, 2007; Wilkins et al., 2012) and the influencing factors (Biggart, 1990; Fairfax, 2001; Cialdini, 2001; Austin, 2004, Legara et al., 2008; Greenspan, 2009; Jacobs \& Schain, 2011; Tennant, 2011; Perri\& Brody, 2012, Daquis et al., 2013; Gunn, 2015). But little is known on the process of Ponzi scheme investors came about to decide to invest in such a scheme.

This condition calls for the researcher to delve beyond the traditional perspective to gain more in-depth knowledge regarding the behaviour of this type of investors. Interestingly, this study offers an alternative view on this matter by proposing the argument investor and consumer share the same cognitive process where both parties are regards as the information processor' (Ribeaux \& Poppleton, 1978). Based on the consumer behaviour theory, this study adopted the cognitive approach as discussed by Bray (2008). He ascertained that there are two cognitive models in this approach namely analytical model and prescriptive model. And this study chooses the analytical model as it aimed to describe a framework of the vital elements in decision-process of Ponzi scheme investors.

One of the widely accepted analytical models is the Consumer Decision Model (Blackwell \& Minniard, 2001). The EBM model served as the foundation of the study in the way that it provides a clear description of the consumption process by including extensive and comprehensive variables. The continuous revision and improvement of the model ever since it was developed has become its significant advantage in investigating consumer behavior.

\section{LITERATURE REVIEW}

\subsection{The Engel-Blackwell-Miniard (EBM) Model}

As previously discussed, this study was guided by the EBM model which was developed by Engel, Kollat, and Blackwell in 1968 (Engel et al., 1968), and also known as The Consumer Decision-making Model. This model was designed to capture the behavior of consumer in using and disposing of product or service by advocating how they are purchased. Howard (1994) stated that the initial model of consumer behavior was designed in the manner of assisting the researcher in understanding buying processes thoroughly and systematically. And the latest version of the EBM model is presented in figure 1: 


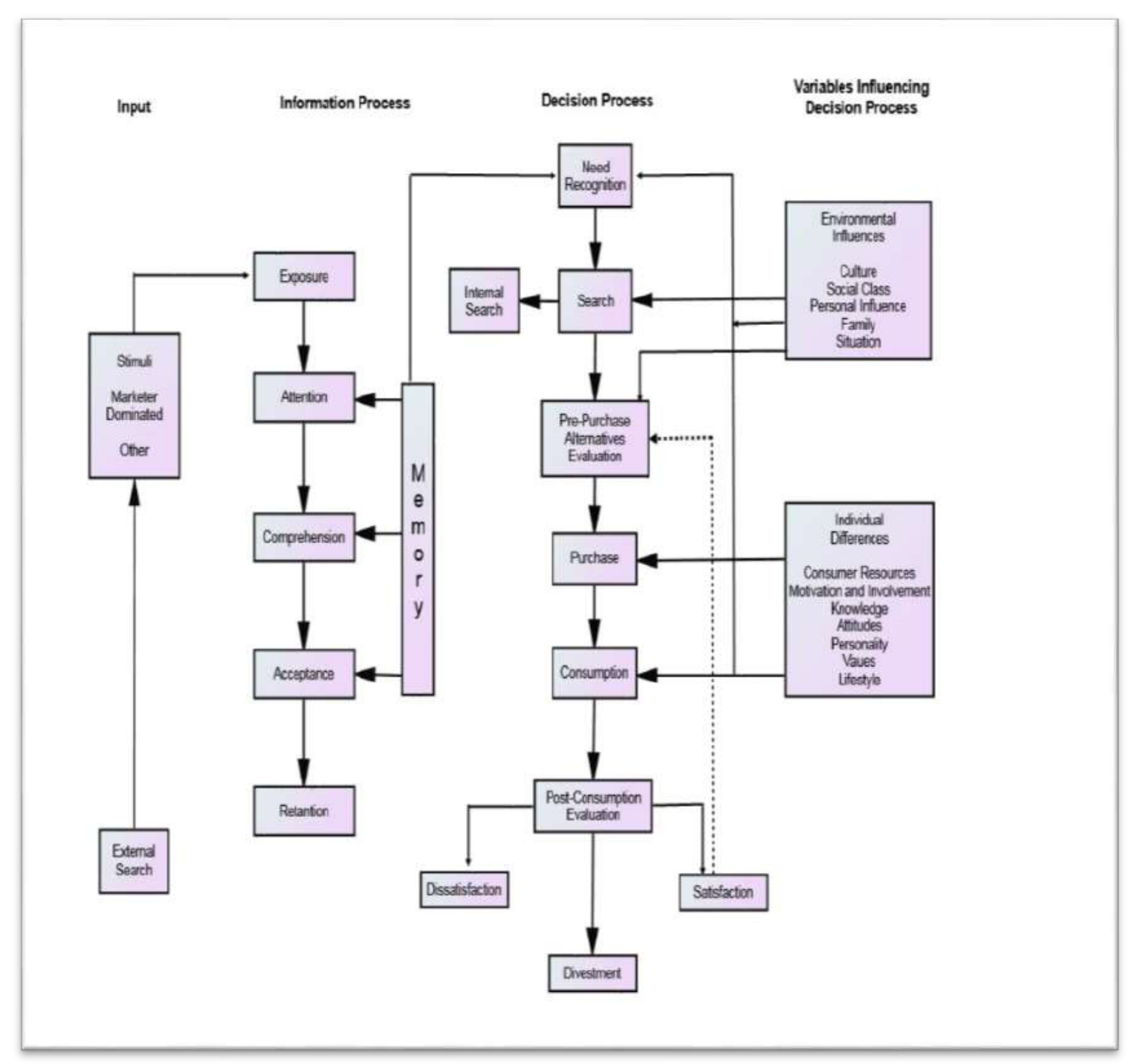

Figure 1 Engel-Blackwell-Miniard (EBM) Model

Source: Blackwell \& Miniard (2001)

Accordingly, the model comprises of seven elements that describes the decision process namely:

- Need Recognition;

- Internal and External Information Search;

- Evaluation of Alternatives;

- Purchase;

- Consumption;

- Post Consumption Reflection;

- Divestment.

Two significant factors affected the decision process which are:

- Input or Stimuli: This factor is received by and processed by individual based on their previous experiences;

- External Variables: This factor is divided into environmental influences and individual influences. The environmental influences consist of culture, social class, personal 
influence, family and situation while the individual influences listed such as consumer resource, motivation and involvement, knowledge, attitudes, personality, values, and lifestyle.

\subsection{The Advantanges and Disadvantages of the (EBM) Model}

The main advantage of this model is that it assists the researcher to structuring theory and designing the research (Mohammadi \& Mohamed, 2011). Till today, the model is widely accepted in previous literature and had undergone continuous evolution. The past researcher had contributed the improvement of the model such as the inclusion of the consumption and divestment factor by embracing contemporary definitions of consumer behavior in their scope (Peter et al., 1999; Schiffman \& Kanuk, 2000; Hogg et al., 2006).

Nevertheless, the model also possesses some disadvantages such as it might not accommodate the variability of decision-making contexts due to its rigid and mechanistic approach (Bray, 2017). It was argued that the linear nature of the model does not comply with the complexity of the decision-making process especially in the modern financial services marketplace (Milner \& Rosenstreich, 2013). And lastly, the model is argued to complicate a straight-forward decision process such as repeated purchases (Erasmus et al., 2013).

\subsection{The EBM Procedure}

This procedure is adapted from the grand model of EBM and was employed by prior research such as Ali and Haibing (2014) and Kontot et al. (2016). There are few versions of the EBM procedure available in scholarly literature. However, this study adopted and adapted the version that was previously used in Ali and Haibing (2014). This version of the EBM procedure consists of five elements that describe a decision process namely: (1) Need recognition: consumers recognize the state of desire that initiates the decision process; (2) Information search: embark on quest for information from the external environment or knowledge stored in memory for potential solutions; (3) Pre-Purchase alternative evaluation: evaluate or judge competing alternatives base on specific criteria related salient beliefs about relevant consequences; (4) Purchase: embark on the chosen alternative; and (5) Post-Purchase alternative evaluation: comparison of the desired product or service performance to the actual performance. The procedure of the EBM model is illustrated in Figure 2.

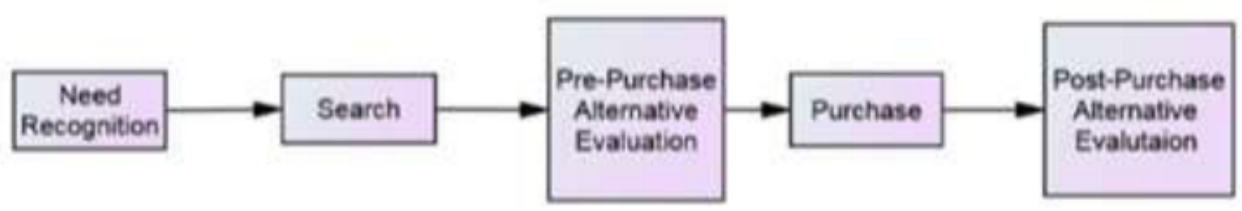

Figure 2 The EBM Procedure

Source: Ali \& Haibing (2014)

\section{CONCEPTUAL FRAMEWORK}

This conceptual framework was developed based on the EBM procedure which was previously adopted by Ali and Haibing (2014) in investigating the decision process of equity investor in Malaysia. The proposed framework suit the nature of the Ponzi scheme investment that differs from the nature of the typical investment such as stocks purchasing. Also, it concurs with the context of describing the decision-process of Ponzi scheme investor. This study proposed four stages of the decision process instead of five in the EBM procedure. The 
four steps of the new decision-process framework consist of (1) need recognition, (2) information search, (3) alternative evaluation, and (3) act to invest as demonstrate in figure 3.

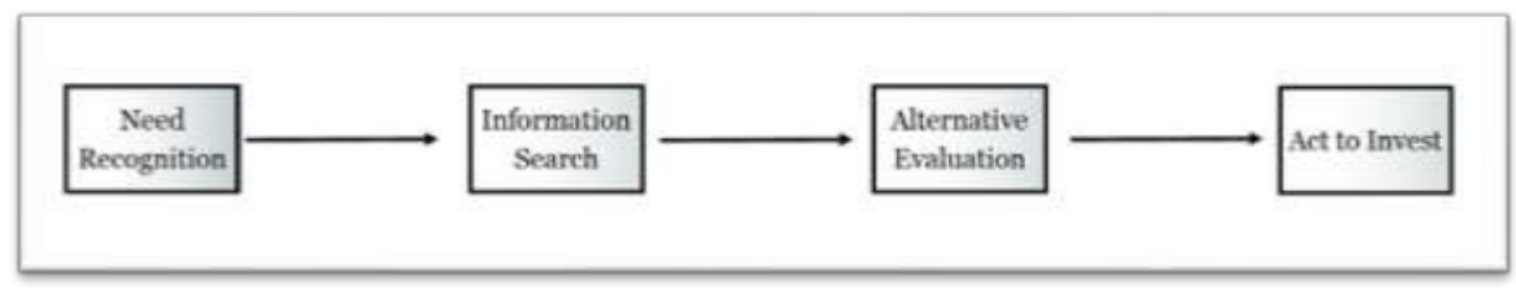

Figure 3. Conceptual Framework of the Study

\section{METHODOLOGY}

This exploratory investigation adopted the case study method with the qualitative approach. The case study method is widely accepted in psychology, sociology, political science, anthropology, social work, business, education, nursing and community planning (Yin, 2014). There are several types of case study categorized across different research field namely, explanatory, descriptive, and exploratory (Yin, 2009). And Yin (2014) suggest that this method is compatible with research that seeks to understand and describe specific and complex social phenomena.

Nevertheless, the qualitative case study is quite estranged in behavioral finance or conventional finance. Unlike its counterpart, the quantitative case study, seems to be more favorable in finance and banking research. Even so, this method was proved to be successful in investigating investor behavior and sentiment as demonstrated by the previous researcher (Tavakoli et al., 2011; Hsieh \& Shannon, 2005).

\subsection{Data Collection Procedure}

A semi-structured interview was adopted as the primary data collection method. Interviews were conducted face-to-face to obtain more in-depth data such as gestures, facial expression and voice intonation as highlighted by Rahman (2015). Furthermore, this method is convenient due to its flexibility and capability to provide an in-depth data set to the study (Dawson, 2010). The instrument for the semi-structured interview was developed based on Ali and Haibing (2014) which was used to describe the purchasing behavior of stock market investor. The initial questionnaire was reviewed by experts and underwent few modifications after incubation of the pilot study.

The questionnaire that was used in the fieldwork study comprises of six main questions. Each question contains sub-questions that probe on specific variable and also serves as prompts to encourage respondents to express further their thought and feelings towards the topic being discussed. The table below will illustrate the interview instrument:

Table 1 Interview Questions

\begin{tabular}{|c|c|c|}
\hline Dimension & Variable & Question \\
\hline \multirow{6}{*}{ Need Recognition } & \multirow{3}{*}{ - Self-actualization } & $\begin{array}{l}\text { 1. What is your first impression/feeling about } \\
\text { the scheme? }\end{array}$ \\
\hline & & Prompt: \\
\hline & & $\begin{array}{l}\text { 1.1 Do you intended to invest in the first } \\
\text { place? }\end{array}$ \\
\hline & \multirow{3}{*}{ - Gain profit } & 2. Why do you want to invest? \\
\hline & & Prompt: \\
\hline & & 2.1 What is your investment goal? \\
\hline http://iaeme.com/1 & urnal/IJM & editor@iaeme.com \\
\hline
\end{tabular}


An Exploratory Inquiry on the Decision Process of Ponzi Scheme Investor's: A Qualitative Case Study Approach

\begin{tabular}{|c|c|c|}
\hline & $\begin{array}{l}\text { - Hedge against } \\
\text { inflation }\end{array}$ & 3. What do you want to do with the profits \\
\hline Information search & $\begin{array}{l}\text { - Personal sources } \\
\text { - Public sources } \\
\text { - Experiential sources } \\
\text { - Commercial sources }\end{array}$ & $\begin{array}{l}\text { 4. Do you have any specific rules/guidelines } \\
\text { before you decide to invest in any scheme? } \\
\text { Prompt: } \\
\text { 4.1 Do you strictly follow the } \\
\text { rules/guidelines? } \\
4.2 \text { How do you develop the } \\
\text { rules/guidelines? }\end{array}$ \\
\hline Alternative Evaluation & $\begin{array}{l}\text { - Background } \\
\text { - Reward and risk } \\
\text { - Cost of investment }\end{array}$ & $\begin{array}{l}5 . \text { What aspect of the scheme that caught } \\
\text { your attention? }\end{array}$ \\
\hline Act to invest & - Amount invested & $\begin{array}{l}\text { 6. Tell me about the latest investment } \\
\text { scheme that you joined. } \\
\text { Prompt: } \\
\text { 6.1 Name of the scheme? } \\
6.2 \text { When invested? } \\
\text { 6.3 Amount invested? } \\
\text { 6.4 Profit gained? } \\
\text { 6.4 Losses incurred? }\end{array}$ \\
\hline
\end{tabular}

This study employed homogenous purposive sampling in selecting seven respondents from the three different Ponzi schemes. Even though the sample size in this study is smaller than the typical qualitative research which normally has a sample size of 15 to 30 individual interview (Braun \& Clarke, 2013), the data collected satisfy the saturation concept proposed by Morse (1995). The definition of saturation based on Morse's definition refers to when additional data unable to generate new information.

\subsection{Case Study Method}

According to Creswell et al. (2007), a case is defined as employing multiple procedures or sources of information in-depth exploration one or more events, programs, activities, entities or individual within an explicit bounded system. Yin (2014) pointed out the strength of the case study method in probing and advocating complex social phenomena such as the Ponzi scheme investment. Denscombe (2014) posit that case study method is widely applied in social science study with regards to its capability to include extensive data collection via multiple sources of information such as interviews, observations, archival records, and related documents.

However, Yin (2009) provide some traditional prejudices against this method such as unable to address the causal relationship and could not satisfy the generalization law, unlike the survey strategy inquiry. Based on this criticism, this study will cautiously interpret and conclude its findings. This research fits with into Type 3 (Multiple cases - Holistic design), in which Pok Din Empire Investment Scheme, U-Fun Investment Scheme, and Khazanah Bangsa Gold Investment Scheme are three holistic units of analysis and each case contributed to the overall scope of the study. One of the advantages of employing this type of case study is the ability to compare and contrast findings between some individual situations being investigated that will yield highly important and fruitful outcomes (Kitay et al., 1998). Case studies are divided into single or multiple case studies with the holistic or embedded unit of analysis which illustrated in Figure 3.1 below. 


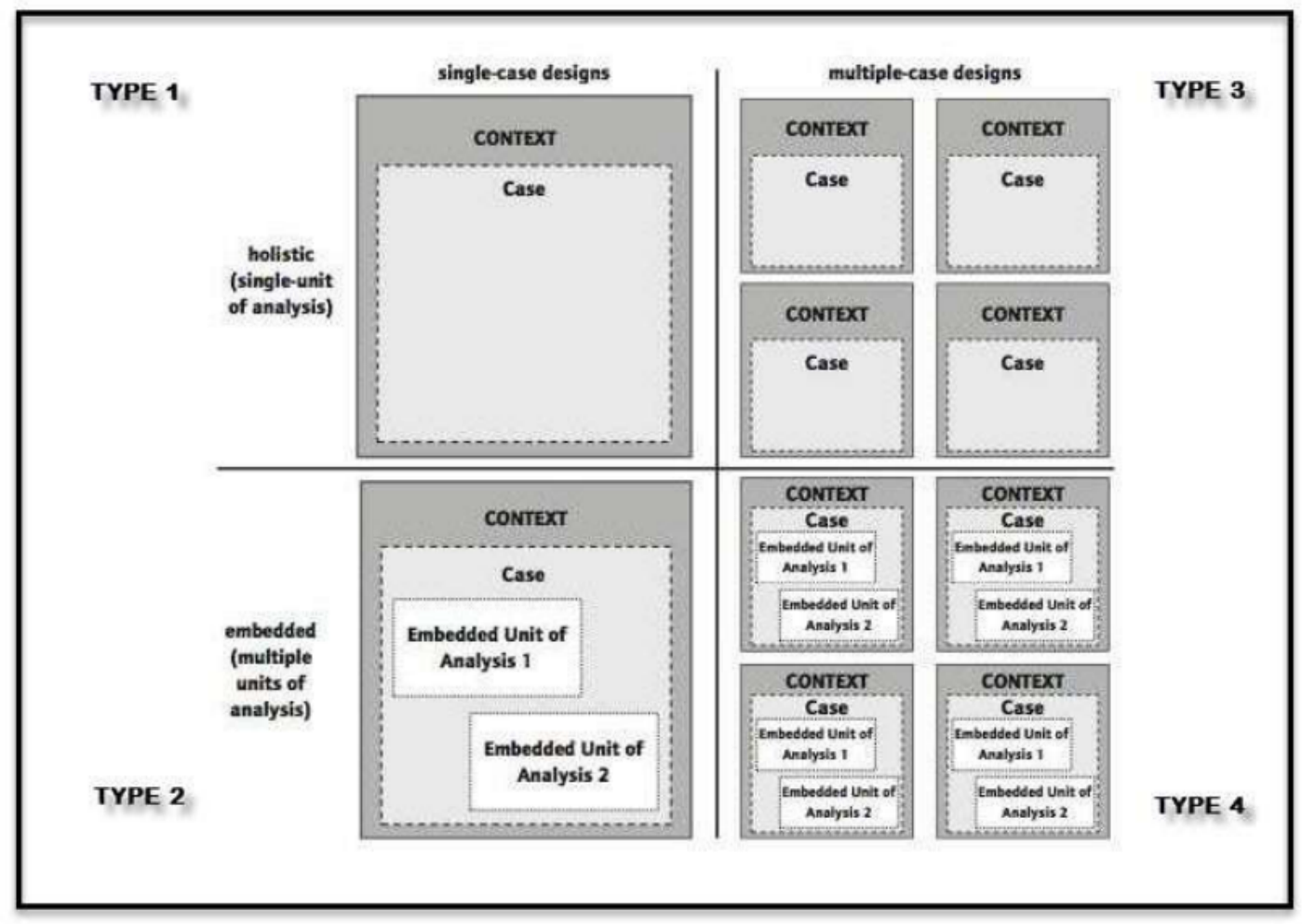

Figure 4 Basic Types of Design for Case Study [36]

\subsubsection{Profile of Case Studies}

Three Ponzi investment schemes were selected as the case studies among 423 schemes listed by the central bank (Bank Negara Malaysia, 2019), namely Pok Din Empire Investment Scheme, U-Fun Investment Scheme, and Khazanah Bangsa Gold Investment Scheme. Table 2 briefly summarized the Ponzi schemes chosen in this study.

Table 2 The Profile of Case Study Chosen

\begin{tabular}{lllcc}
\hline \multicolumn{1}{c}{$\begin{array}{c}\text { Name of the } \\
\text { Scheme }\end{array}$} & \multicolumn{1}{c}{$\begin{array}{c}\text { Name of the } \\
\text { Company }\end{array}$} & \multicolumn{1}{c}{ Scheme's Characteristics } & Blacklisted Date & $\begin{array}{c}\text { The Number on the } \\
\text { BNM's List }\end{array}$ \\
\hline $\begin{array}{l}\text { Pok Din Empire } \\
\text { Investment }\end{array}$ & $\begin{array}{l}\text { Pok Din Empire } \\
\text { Sdn Bhd }\end{array}$ & $\begin{array}{l}\text { Operated money game based on } \\
\text { the e-commerce platform }\end{array}$ & 27.05 .2016 & 284 \\
$\begin{array}{l}\text { U-Fun Investment } \\
\text { Scheme }\end{array}$ & Ufun Club & $\begin{array}{l}\text { Switched cash from new } \\
\text { investors using e-currency } \\
\text { platform }\end{array}$ & 25.07 .2014 & 389 \\
$\begin{array}{l}\text { Khazanah Bangsa } \\
\text { Gold Investment } \\
\text { Scheme }\end{array}$ & $\begin{array}{l}\text { Darul Emas } \\
\text { Perak Berhad }\end{array}$ & $\begin{array}{l}\text { Switched cash from new } \\
\text { investors using a gold trading } \\
\text { platform }\end{array}$ & 19.02 .2014 & 78 \\
\hline
\end{tabular}

\subsection{Operational Definition}

At this point, the operational definition of the decision process for Ponzi scheme investors is developed based on the conceptual framework and prior literature of the EBM procedure. The operational definition for decision-process is presented as follows: 
An Exploratory Inquiry on the Decision Process of Ponzi Scheme Investor's: A Qualitative Case Study Approach

Table 2 Operational Definition for Decision Process

\begin{tabular}{|c|c|c|}
\hline Construct & Dimensions & Variables \\
\hline \multirow[t]{4}{*}{ Decision Process } & Need Recognition & $\begin{array}{l}\text { - Self-actualization } \\
\text { - Gain profit } \\
\text { - Hedge against inflation }\end{array}$ \\
\hline & Information Search & $\begin{array}{l}\text { - Personal sources } \\
\text { - Public sources } \\
\text { - Experiential sources }\end{array}$ \\
\hline & Alternative Evaluation & $\begin{array}{l}\text { - Commercial sources } \\
\text { - Background of the scheme } \\
\text { - Reward and risk } \\
\text { - Cost of investment } \\
\text { - Amount invested }\end{array}$ \\
\hline & Act to Invest & - Amount invested \\
\hline
\end{tabular}

\section{DATA ANALYSIS}

Directed content analysis approach was adopted in addressing the research objective of the study. This approach is part of the variability of the content analysis method which is compatible in studying a phenomenon that had been theoretically explained and empirically investigated but needed a further description (Hsieh \& Shannon, 2005). In this case, the theory that guided this research is the consumer behavior theory (EBM Grand Model) which has already been extensively discussed by previous the researcher. Prior research such as Muda et al. (2003) and Ali and Haibing (2014) will act as the basis for designing current research questions and provide a prediction about the variable understudied or the association between variables.

As defined by Strauss (1987), content analysis is a qualitative data analysis process which the researcher examines artifacts of social communication such as a set of written documents or transcriptions of recorded verbal communication. Additionally, content analysis is claimed to a robust empirical method for identifying, extracting and analyzing text (Thayer et al., 2007). With the assistance of ATLAS.ti software, the directed content analysis approach is convenient in the way of connecting, structuring, and synchronizing evidence that could help to expose hidden relationship among concepts and ideas that seem unconnected at first.

The findings from this type of content analysis offer validation or extension of a theoretical framework by computing supporting and non-supporting evidence for a particular theory being studied. On top of it, the process of conducting directed content analysis is a more structured process because it is guided by existing theory or previous research (Hickey \& Kipping, 1996).

\subsection{Deductive Coding}

Before the transcripts were analyzed using the ATLAS.ti software, an initial coding scheme was prepared based on the operational definition of each construct. This process is compulsory in the directed content analysis approach as suggested by Hsieh and Shahnon (2005). The deductive coding process is conducted using the selective coding function in ATLAS.ti. The table below breakdown the details of the assigned codes. 
Table 3 Deductive Codes and Explanation

\begin{tabular}{|c|c|c|c|}
\hline Codes Family & Dimensions & Codes & $\begin{array}{c}\text { Explanation } \\
\end{array}$ \\
\hline \multirow{3}{*}{ Decision Process } & \multirow{3}{*}{ Need Recognition } & NRs & The presence of self-actualization variable. \\
\hline & & NRg & The presence of gain profit variable. \\
\hline & & $\mathrm{NRh}$ & $\begin{array}{l}\text { The presence of hedge against inflation } \\
\text { variable. }\end{array}$ \\
\hline \multirow{4}{*}{ Decision Process } & \multirow{4}{*}{ Information Search } & ISper & The presence of personal sources variable. \\
\hline & & ISpub & The presence of public sources variable. \\
\hline & & ISexp & $\begin{array}{l}\text { The presence of experiential sources } \\
\text { variable. }\end{array}$ \\
\hline & & IScom & $\begin{array}{l}\text { The presence of commercial sources } \\
\text { variable. }\end{array}$ \\
\hline \multirow{3}{*}{ Decision Process } & \multirow{3}{*}{ Alternative Evaluation } & AEbac & $\begin{array}{l}\text { The presence of background of the scheme } \\
\text { variable. }\end{array}$ \\
\hline & & AErew & The presence of reward and risk variable. \\
\hline & & AEcos & $\begin{array}{l}\text { The presence of cost of investment } \\
\text { variable. }\end{array}$ \\
\hline Act to Invest & Amount Invested & Amount & $\begin{array}{l}\text { The presence of investment evidence } \\
\text { (capital invested). }\end{array}$ \\
\hline
\end{tabular}

\subsection{Inductive Coding}

No analyzed text that was found during the deductive coding process that could not be categorized using the deductive coding. Hence, there were no new codes assigned to the interpreted text. In other words, there is no new uncategorized evidence derived from the deductive coding process.

\section{FINDINGS}

\subsection{Respondent's Profile}

Seven Ponzi scheme investors were interviewed about their decision process in a Ponzi investment scheme, and their profile is presented in Table 2. Of these investors, only one of them does not have a higher educational background. All respondents are Malay, five are male, and two are female. The majority of them works in the government sector, aged between 20 and 39 years old.

Table 4. Respondent's Profile

\begin{tabular}{lccc}
\hline & Variables & Frequency & Percentage (\%) \\
\hline Age: & 20-29 years old & 1 & 14.28 \\
& 30-39 years old & 6 & 85.71 \\
Race: & Malay & 1 & 100 \\
Gender: & Male & 5 & 60 \\
& & & \\
http://iaeme.com/Home/journal/IJM & 228 & & editor@iaeme.com
\end{tabular}


An Exploratory Inquiry on the Decision Process of Ponzi Scheme Investor's: A Qualitative Case Study Approach

Marital Status:

Female

2

40

Single

1

14.28

Married

85.71

Educational Level:

SPM

14.28

Diploma

Bachelor Degree

28.57

57.14

Occupational Sector:

Private 1

14.28

Government

71.42

Self-Employed

14.28

Working Experience:

$$
1-5
$$

6-10

85.71

Monthly Income:

Below RM1000
RM1000 - RM4999
RM5000 - RM9999
RM10000 - RM14999
RM15000 - RM19999
Above RM20000

1

0

57.14

42.86

0

0

\subsection{Supporting Evidence based on Dimensions and Variables.}

\subsubsection{Need Recognition}

Table 5 Evidence for Need Recognition

\begin{tabular}{|c|c|c|c|}
\hline Variables & Codes & $\begin{array}{l}\text { Respondent Code } \\
\text { (Verbatim) }\end{array}$ & Quotations \\
\hline $\begin{array}{l}\text { Self- } \\
\text { actualization }\end{array}$ & NRs & $1 \& 6$ & $\begin{array}{l}\text { P 1: Verbatim Transcript 1.docx - 1:5 (27:27) } \\
\text { Uh-huh, because of her-I helped by } \\
\text { monitoring Facebook ((pause)) I'm afraid } \\
\text { she'll lose her money. Eventually, I decided to } \\
\text { join. } \\
\text { P 6: Verbatim Transcript 6.docx - 6:5 (25:25) } \\
\text { Uh-huh, I want to help my parent. }\end{array}$ \\
\hline Gain profit & $\mathrm{NRg}$ & $3,4,5, \& 7$ & $\begin{array}{l}\text { P 3: Verbatim Transcript 3.docx - } 3: 5 \text { (28:28) } \\
\text { And I planned to sell something in Pok Din's } \\
\text { community. } \\
\text { P 4: Verbatim Transcript 4.docx - 4:5 (25:25) } \\
\text { I'm interested with the returns. } \\
\text { P 5: Verbatim Transcript } 5 . \text { docx - 5:5 }(25: 25) \\
\text { Because of the high return on investment. } \\
\text { P 7: Verbatim Transcript 7.docx - 7:5 (25:25) } \\
\text { So when I was offered, I was excited. Excited } \\
\text { because I can make a side income. }\end{array}$ \\
\hline $\begin{array}{l}\text { Hedge against } \\
\text { inflation }\end{array}$ & $\mathrm{NRh}$ & 2 & $\begin{array}{l}\text { P 2: Verbatim Transcript 2.docx - } 2: 5(25: 25) \\
\text { Um, because I am in need of some cash. }\end{array}$ \\
\hline
\end{tabular}




\subsubsection{Information Search}

Table 6 Evidence for Information Search

\begin{tabular}{|c|c|c|c|}
\hline Variables & Codes & $\begin{array}{c}\text { Respondent Code } \\
\text { (Verbatim) }\end{array}$ & Quotations \\
\hline Personal sources & ISper & $1,2,3,4,5,6 \& 7$ & $\begin{array}{l}\text { P 1: Verbatim Transcript 1.docx - 1:6 (30:30) } \\
\text { Then, if they insisted, I will ask if they are } \\
\text { registered with CCM (Company Corporation of } \\
\text { Malaysia) ((pause)) Um, any other detailed } \\
\text { information ((pause)) that will satisfy me, I will } \\
\text { ask. } \\
\text { P 2: Verbatim Transcript 2.docx - 2:17 (28:28) } \\
\text { First of all, I will study it first. } \\
\text { P 3: Verbatim Transcript 3.docx - 3:6 (31:31) } \\
\text { Indeed, I did some research. But the name Pok } \\
\text { Din did not come up in online, at that time. } \\
\text { P 4: Verbatim Transcript 4.docx - 4:6 (28:28) } \\
\text { I will search for information myself. Means that, I } \\
\text { will do some research first ((paused)). Um, I did. } \\
\text { P 5: Verbatim Transcript 5.docx - 5:6 (30:30) } \\
\text { I (.) actually did some research through Facebook. } \\
\text { P 6: Verbatim Transcript 6.docx - 6:19 (28:28) } \\
\text { I search for the details first. Uh-huh, I look for } \\
\text { information first. } \\
\text { P 7: Verbatim Transcript 7.docx - 7:6 (32:32) } \\
\text { Facebook, Google. I studied about ((pause)) the } \\
\text { details of the company. Checked the CCM. }\end{array}$ \\
\hline Public sources & ISpub & 0 & \\
\hline $\begin{array}{l}\text { Experiential } \\
\text { sources }\end{array}$ & ISexp & 0 & \\
\hline $\begin{array}{l}\text { Commercial } \\
\text { sources }\end{array}$ & IScom & 0 & \\
\hline
\end{tabular}

\subsubsection{Alternative Evaluation}

Table 7. Evidence for Alternative Evaluation

\begin{tabular}{|c|c|c|c|}
\hline Variables & Codes & $\begin{array}{l}\text { Respondent Code } \\
\text { (Verbatim) }\end{array}$ & Quotations \\
\hline $\begin{array}{l}\text { Background of } \\
\text { the scheme }\end{array}$ & AEbac & $2,4,5,6, \& 7$ & $\begin{array}{l}\text { P 2: Verbatim Transcript 2.docx - 2:7 (31:31) } \\
\text { I don't like either if others recruiting me. It looks } \\
\text { desperate. What happened with Pok Din, I was not } \\
\text { recruited, I discovered it, and I am interested with } \\
\text { it, so I joined it. } \\
\text { P 4: Verbatim Transcript 4.docx - 4:7 (31:31) } \\
\text { And U-token was said to be a lot easier than } \\
\text { FOREX. } \\
\text { P 5: Verbatim Transcript 5.docx - 5:7 (33:33) } \\
\text { She just recommended to me whether Tok } \\
\text { Berlagak or KB. I never heard of KB before this. } \\
\text { P 6: Verbatim Transcript } 6 . d o c x-6: 8 \text { ( } 31: 31) \\
\text { I considered Tok Berlagak and MKI because they } \\
\text { share the same modus operandi. Only the leader } \\
\text { was different - based on their modus operandi. } \\
\text { P 7: Verbatim Transcript } 7 . d o c x-7: 7 \text { (35:35) } \\
\text { I invested into three companies. }\end{array}$ \\
\hline
\end{tabular}

Reward and risk $\quad$ AErew $1 \& 3 \quad$ P 1: Verbatim Transcript 1.docx - 1:7 (33:33) 
An Exploratory Inquiry on the Decision Process of Ponzi Scheme Investor's: A Qualitative Case Study Approach

So I thought it is better I invested myself rather than to give her. Uh-huh, I invested under my name.

P 3: Verbatim Transcript 3.docx - 3:7 (36:36)

Uh-huh, good investment is-from the perspective of returns on investment. The bigger the returns-it is better.

Cost of AEcos 0

investment

\subsubsection{Act to Invest}

Table 8. Evidence for Act to Invest

\begin{tabular}{|c|c|c|c|}
\hline Variables & Codes & $\begin{array}{c}\text { Respondent Code } \\
\text { (Verbatim) }\end{array}$ & Quotations \\
\hline $\begin{array}{l}\text { Amount } \\
\text { Invested }\end{array}$ & Amount & $1,2,3,4,5,6, \& 7$ & $\begin{array}{l}\text { P 1: Verbatim Transcript 1.docx - 1:8 (37:37) } \\
\text { I invested five thousand (.) five thousand (.) } \\
\text { um, ringgit. Then converted into five } \\
\text { thousand } E P \text { and I shot, I got eight thousand. } \\
\text { P 2: Verbatim Transcript 2.docx - 2:8 (34:34) } \\
\text { Um, I think about ten thousand } \\
\text { P 3: Verbatim Transcript 3.docx - 3:8 (39:39) } \\
\text { Um, as far as I concern, it is about two } \\
\text { thousand. About two thousand, then I got the } \\
\text { returns. } \\
\text { P 4: Verbatim Transcript 4.docx - 4:20 } \\
\text { (34:34) } \\
\text { When we - For example we invested an } \\
\text { amount of - like me I invested not that much } \\
\text { ((pause)) about two thousand ringgit. } \\
\text { P 5: Verbatim Transcript 5.docx - 5:17 } \\
\text { (36:36) } \\
\text { Um, it is twenty four thousand. } \\
\text { P 6: Verbatim Transcript 6.docx - 6:18 } \\
\text { (34:34) } \\
\text { Three thousand plus. } \\
\text { P 7: Verbatim Transcript 7.docx - 7:17 } \\
\text { (38:38) } \\
\text { Forty two thousand nine hundred. }\end{array}$ \\
\hline
\end{tabular}

\subsection{Determining the Hierarchy for All Variables}

Using the code co-occurrence analysis, this study established the codes co-occurency table to determine the frequency of code co-occurrence for all variables. The result of the analysis is presented in the following tables and figure.

Table 9. Codes Co-Occurrency

\begin{tabular}{|c|c|c|c|c|c|c|c|c|}
\hline Respondents & AEbac & AErew & Amount & ISpub & NRg & NRh & NRs & TOTALS: \\
\hline KBGIS 1 & 0.13 & 0 & 0.1 & 0.1 & 0.14 & 0 & 0 & 0.47 \\
\hline KBGIS 2 & 0.13 & 0 & 0.1 & 0.1 & 0 & 0 & 0.2 & 0.53 \\
\hline KBGIS 3 & 0.13 & 0 & 0.1 & 0.1 & 0.14 & 0 & 0 & 0.47 \\
\hline PDEIS 1 & 0 & 0.2 & 0.1 & 0.1 & 0 & 0 & 0.2 & 0.6 \\
\hline PDEIS 2 & 0.13 & 0 & 0.1 & 0.1 & 0 & 0.25 & 0 & 0.57 \\
\hline PDEIS 3 & 0 & 0.2 & 0.1 & 0.1 & 0.14 & 0 & 0 & 0.54 \\
\hline UFIS 1 & 0.13 & 0 & 0.1 & 0.1 & 0.14 & 0 & 0 & 0.47 \\
\hline
\end{tabular}


Table 10 Frequency of Codes Co-Occurrence for All Variables

\begin{tabular}{lc}
\hline \multicolumn{1}{c}{ Codes } & Frequency \\
\hline AEbac & 5 \\
AErew & 2 \\
Amount & 7 \\
ISpub & 7 \\
NRg & 4 \\
NRh & 1 \\
NRs & 2 \\
\hline
\end{tabular}

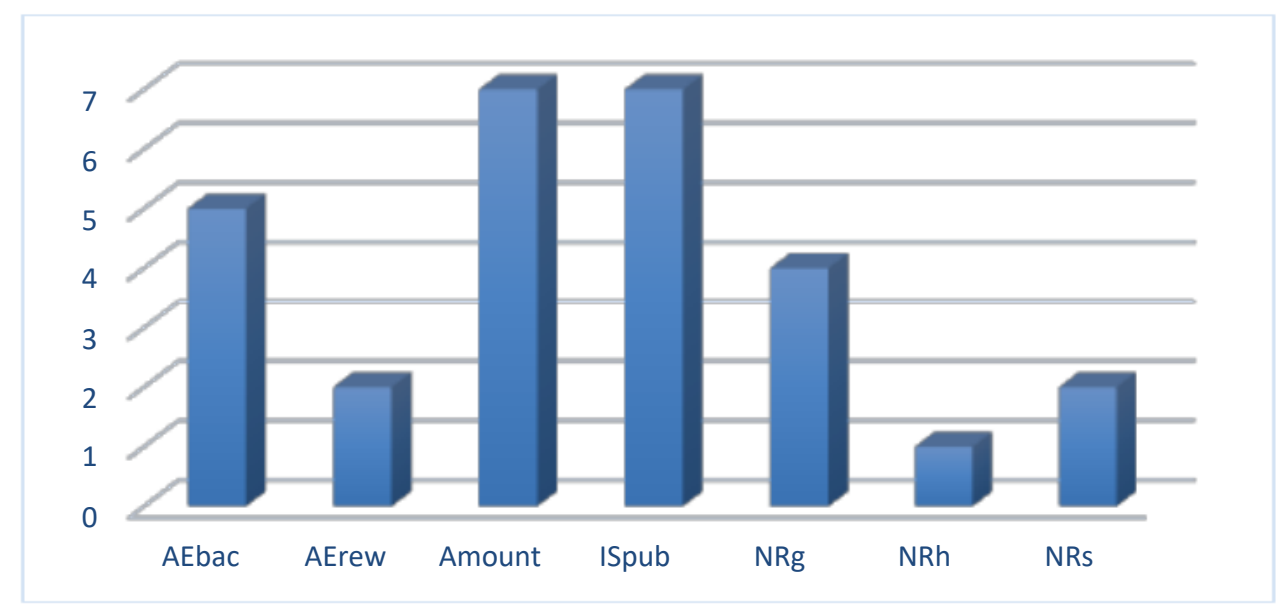

Figure 3 Frequency of Codes Co-occurrence for All Variables

This analysis indicated that the strongest variable for Need Recognition is Gain Profit and the weakest variable is Hedge against Inflation. As for the Information Search, the only variable that was found is Public Sources. With regards to Alternative Evaluation, the Background of the Scheme revealed to be the strongest variable and the weakest variable is the Rewards and Risk.

As mentioned earlier, there was no inductive coding identified in this study. Thus, for Act to Invest, the Amount Invested is the only variable and no hierarchy for this dimension.

\subsection{Summarizing all the Evidence}

Sequentially, the evidence of the study is connected and presented using a diagram like the following figure:

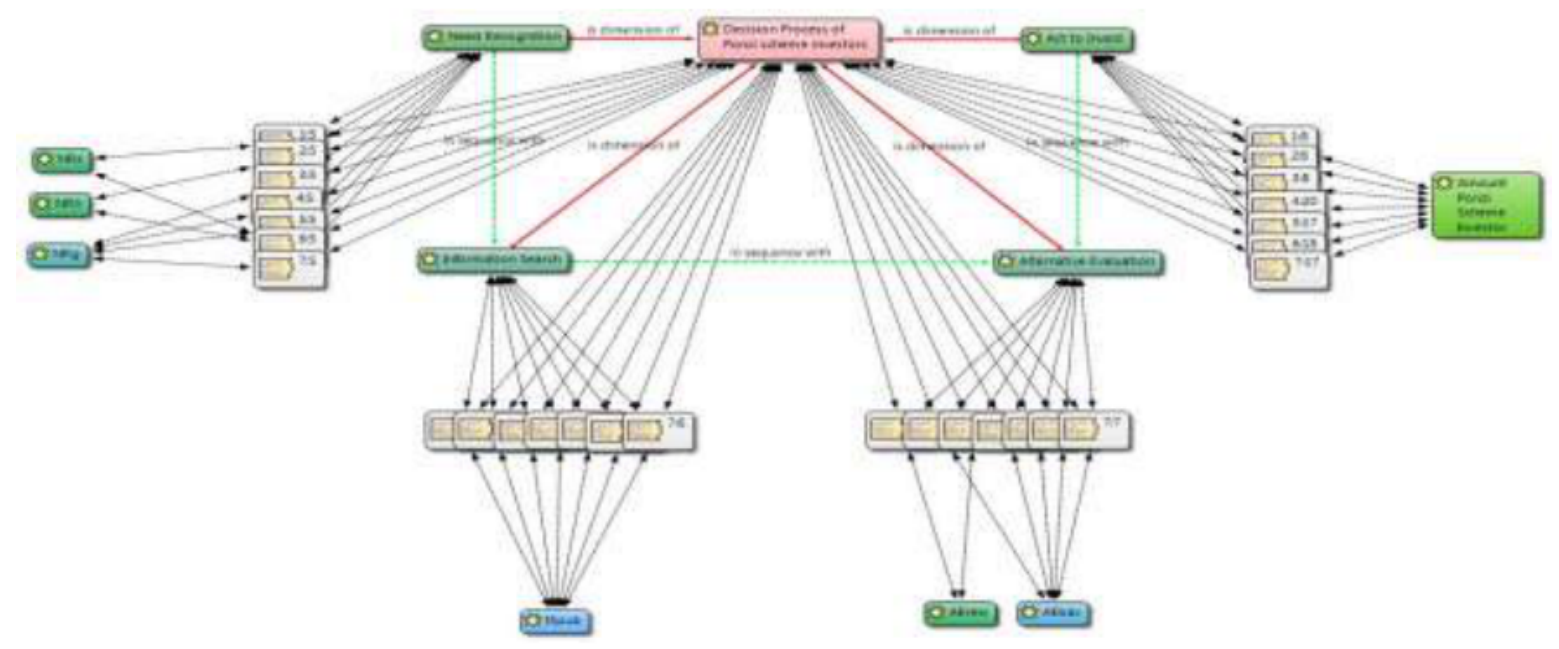

Figure 3. Summary of Findings for Decision Process of Ponzi scheme Investor 


\subsection{The Proposed Framework for Ponzi Scheme Investor's Decision Process}

Derived from the network diagram built in ATLAS.ti, the framework of the study is proposed and presented as the following figure:

Variables

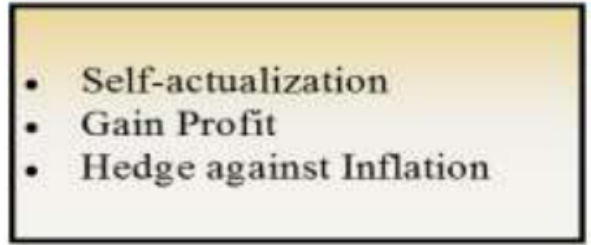

- Personal Sources
Decision Process
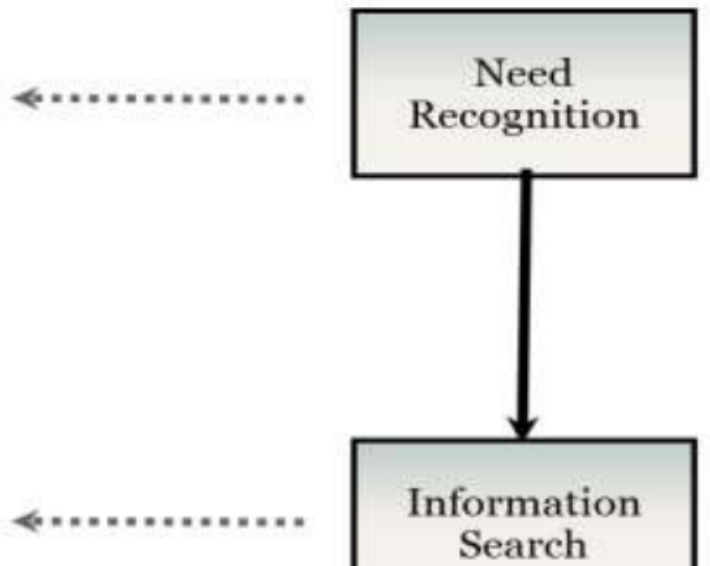

Information Search

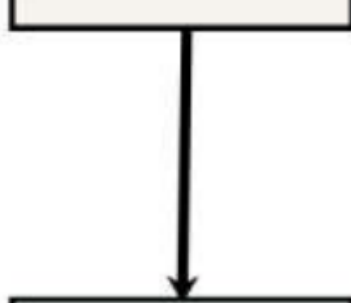

Alternative Evaluation

- Background of the Scheme

- Reward and Risk

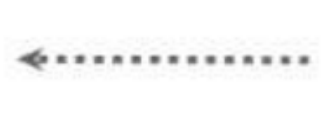

- Amount Invested

Act to

Invest

Figure 4 The Proposed Framework for Ponzi Scheme Investor's Decision Process

\section{DISCUSSION AND CONCLUSION}

This study takes a modest and cautious approach in concluding its findings as this is the exploratory investigation that intended to describe the decision process of Ponzi scheme investor. Even though all supporting evidence for all dimensions was obtained from the data collection, it cannot be generalized to the whole population as it is difficult for a qualitative approach to comply with the generalization law (Yardley, 2008). As the evidence suggests, it 
is reasonable to propose that the decision process of Ponzi scheme investor in this study fits with modified EBM procedure.

The modified EBM procedure provides a useful foundation to describe the complex and sophisticated behavior of Ponzi scheme investors by structuring their decision-process into a mechanistic approach. Even so, this study acknowledged the fact that the real-life decision process of Ponzi scheme investors might not be necessarily straightforward and structured in a sequence as argues by other researchers (Brinberg, \& Lutz, 2012; Phillips \& Bradshaw, 1993). As pointed out by Bray (2008), Milner and Rosenstreich (2013), and Eramus et al. (2001), the EBM model arguably claimed to be unable to capture the variation of decisionmaking in the context of complex circumstances that most of the investors face in the current financial services marketplace.

The current study did not examine other factors that could be accounted for the variability of the decision-making context. As per se, the context might be different between experienced investors and novice investors. Thus, it will provide an opportunity for future research to examine the influence of individual differences such as personality, attitudes, and lifestyle as suggested by the EBM grand model.

On the whole, this study provides an alternative perspective in investigating Ponzi scheme investors as prior research in this area commonly conducted from the standpoint of legal and criminology view. As for the concluding remark, the authors call for more research regarding the Ponzi scheme investor to gain a deeper understanding in their behavior as it may contribute to the development of policy or educational strategy that could alleviate future investor participation and losses in fraudulent investments.

\section{REFERENCES}

[1] Abdul Ghani, M. T. \& Abdul Halim, B. (2017). Pseudo-investment scheme in malaysia: Issues and problems, Jurnal Sultan Alaudin Sulaiman Shah, 4(1), 60-66.

[2] Ali, R. \& Haibing, J. (2014). A study of investor behavior in purchasing financial assets. Journal of Finance and Financial Services, 1(1),55-70.

[3] Austin, D. E. (2004). In god we trust: The cultural and social impact of affinity fraud in the african american church. U. Md. LJ Race, Religion, Gender \& Class, 4, 365.

[4] Bank Negara Malaysia. 2019. Financial consumer alert: List of companies and websites which are neither authorised nor approved under the relevant laws and regulations administered by BNM. www.bnm.gov.my/documents/2019/20190527_FCA_EN.pdf

[5] Blackwell, R., \& Miniard, P. W. (2001). Consumer Behavior. 9th Ed. Orlando: Harcourt.

[6] Bray, J. (2008). Consumer Behavior Theory: "Approaches and Models", available: http://eprints.bournemouth.ac.uk/10107/1/.

[7] Braun, V., \& Clarke, V. (2013). Successful qualitative research: A practical guide for beginners. Sage.

[8] Biggart, N. W. (1990). Capitalism in contrasting cultures: direct selling in the US and Asia. Capitalism in Contrasting Cultures, Redding, Gordon and Clegg, Stewart, eds. New York: Walter de Gruyter, 409-428.

[9] Brinberg, D., \& Lutz, R. J. (Eds.). (2012). Perspectives on methodology in consumer research. Springer Science \& Business Media.

[10] Cortés, D., Santamaría, J., \& Vargas, J. F. (2016). Economic shocks and crime: Evidence from the crash of Ponzi schemes. Journal of Economic Behavior \& Organization, 131, 263-275.

[11] Creswell, J. W., Hanson, W. E., Clark Plano, V. L., \& Morales, A. (2007). Qualitative research designs: Selection and implementation. The counseling psychologist, 35(2), 236-264.

[12] Cialdini, R. B. (2001). The science of persuasion. Scientific American, 284(2), 76-81. 
An Exploratory Inquiry on the Decision Process of Ponzi Scheme Investor's: A Qualitative Case Study Approach

[13] Daquis, J. C. P., Castañeda, A. O., Sy, N. D., \& Abgona, R. J. V. (2013). Profitability and growth topology analysis of unilevel-type of network marketing structures. The Philippine Statistician, 62(2), 13-29.

[14] Dawson, A. (2010). A case study of impact measurement in a third sector umbrella organisation. International Journal of Productivity and Performance Management, 59(6), 519533.

[15] Denscombe, M. (2014). The good research guide: For small-scale social research projects (Open UP Study Skills). McGraw-Hill.

[16] Engel, J. F., Kollat, D. T., \& Blackwell, R. D. (1968). Consumer Behavior. New York, Holt: Rinehart and Winston, Inc.).

[17] Erasmus, A. C., Boshoff, E., \& Rousseau, G. G. (2001). Consumer decision-making models within the discipline of consumer science: A critical approach. Journal of Consumer Sciences, 29(1).

[18] Fairfax, L. M. (2001). With friends like these...: Toward a more efficacious response to affinity-based securities and investment fraud. Ga. L. Rev., 36, 63.

[19] Frankel, T. (2012). The Ponzi scheme puzzle: A history and analysis of con artists and victims. Oxford University Press.

[20] Gunn, G. (2015). Broken People, Deep Scars, Fractured Communities, Fear and Distrust: Affinity Fraud and the Church of Jesus Christ of Latter-Day Saints. Retrieved from: https://papers.ssrn.com/sol3/papers.cfm?abstract_id=2562462. [Accessed: May 4, 2017].

[21] Greenspan, S. (2009). Fooled by ponzi: How bernard madoff made off with my money, or why even an expert on gullibility can get gulled. Skeptic (Altadena, CA), 14(4), 20-26.

[22] Hickey, G., \& Kipping, C. (1996). Issues in research. A multi-stage approach to the coding of data from open-ended questions. Nurse Researcher, 4, 81-91.

[23] Hogg, M., Askegaard, S., Bamossy, G., \& Solomon, M. (2006). Consumer behaviour: a European perspective. Prentice Hall.

[24] Howard, J. A. (1994). Buyer behavior in marketing strategy. Prentice Hall.

[25] Hsieh, H. F., \& Shannon, S. E. (2005). Three approaches to qualitative content analysis. Qualitative health research, 15(9), 1277-1288.

[26] Jacobs, P., \& Schain, L. (2011). The Never Ending Attraction of the Ponzi Scheme. Journal of Comprehensive Research, 9, 40-46.

[27] Jory, S., \& Perry, M. J. (2011). Ponzi schemes: A critical analysis. Journal of Financial Planning.Retrieved. from.https://papers.ssrn.com/sol3/papers.cfm?abstract_id=1894206

[28] Kitay, J., Callus, R., Whitfield, K., \& Strauss, G. (1998). The Role and Challenge of Case Study Design in (pp. 101-112). Ithaca, NY: Cornell University Press.

[29] Kontot, K., Hamali, J., \& Abdullah, F. (2016). Determining factors of customers' preferences: a case of deposit products in islamic banking. Procedia-Social and Behavioral Sciences, 224, 167-175.

[30] Legara, E. F., Monterola, C., Juanico, D. E., Litong-Palima, M., \& Saloma, C. (2008). Earning potential in multilevel marketing enterprises. Physica A: Statistical Mechanics and its Applications, 387(19-20), 4889-4895.

[31] Lewis, M. K. (2012). New dogs, old tricks. Why do ponzi schemes succeed?. In Accounting forum, Elsevier, 36 (4), 294-309.

[32] Loyle, D. (2007). Individual investors: A bull market. Target Marketing, 30, 11, 45.

[33] Milner, T., \& Rosenstreich, D. (2013). A review of consumer decision-making models and development of a new model for financial services. Journal of Financial Services Marketing, 18(2), 106-120.

[34] Mohammadi, A. M., \& Mohamed, B. (2011). Applying consumer behavior theory and grand models to attendees' behavior in conference industry. Tourism \& Management Studies, 151159. 
[35] Morse, J.M. (1995). The significance of saturation, Qualitative Health Research 5(2): 147-9.

[36] Muda, M., Aziz, M.Y.A., \& Rozali, M.H. 2003. A study of quick-rich scheme in peninsular Malaysia (UPU(1)/C/2001). Pandan Indah; Kuala Lumpur. Kolej Universiti Islam Malaysia.

[37] Naylor, R. T. (2007). The alchemy of fraud: Investment scams in the precious-metals mining business. Crime, law and social change, 47(2), 89-120.

[38] Phillips, H. and Bradshaw, R. (1993) How customers actually shop: Customer interaction with the point of sale. Journal of the Market Research Society, 35 (1): 51 - 62.

[39] Perri, F. S., \& Brody, R. G. (2012). The optics of fraud: affiliations that enhance offender credibility. Journal of Financial Crime, 19(4), 355-370.

[40] Peter, J. P., Olson, J. C., \& Grunert, K. G. (1999). Consumer behaviour and marketing strategy (pp. 329-48). London: McGraw-Hill.

[41] Rahman, S. A. B. A. (2015). Awareness, practices and treatment of extra-role behavior (erb) in performance measurement systems (pms) of malaysian small and medium enterprises (sme) (Doctoral dissertation, University of Strathclyde).

[42] Reurink, A. (2018). Financial fraud: A literature review. Journal of Economic Surveys, 32(5), $1292-1325$.

[43] Ribeaux, P., \& Poppleton, S. E. (1978). Psychology and Work: An introduction. London: Macmillan.

[44] Sadiraj, K., \& Schram, A. (2001). Informed and uninformed investors in an experimental Ponzi scheme. ACE Programme Management.

[45] Schiffman, L. G., \& Kanuk, L. L. (2000). Consumer behavior, (7th ed). New York: Prentice Hall.

[46] Strauss, A. L. (1987). Qualitative analysis for social scientists. Cambridge University Press.

[47] Tavakoli, M. R., Habibi Tanha, F., \& Halid, N. (2011). A study on small investors' behavior in choosing stock case study: Kuala-Lumpur stock market. African Journal of Business Management, 5(27), 11082-11092.

[48] Tennant, D. (2011). Why do people risk exposure to Ponzi schemes? Econometric evidence from Jamaica. Journal of International Financial Markets, Institutions and Money, 21(3), 328346.

[49] Thayer, A., Evans, M., McBride, A., Queen, M., \& Spyridakis, J. (2007). Content analysis as a best practice in technical communication research. Journal of Technical Writing and Communication, 37(3), 267-279.

[50] Trahan, A., Marquart, J. W., \& Mullings, J. (2005). Fraud and the American dream: Toward an understanding of fraud victimization. Deviant Behavior, 26(6), 601-620.

[51] Wilkins, A. M., Acuff, W. W., \& Hermanson, D. R. (2012). Understanding a ponzi scheme: Victims' perspectives. Journal of Forensic \& Investigative Accounting, 4(1), 1-19.

[52] Yardley, L. (2008). Demonstrating validity in qualitative psychology. Qualitative psychology: A practical guide to research methods, 2, 235-251.

[53] Yin, R. K. (2009). Case study research: Design and methods (applied social research methods). London and Singapore: Sage.

[54] Yin, R. K. (2014). Case study research: Design and methods (Fifth). Thousand Oaks, CA: Sage Publications. 